\title{
Como Erradicar o Trabalho Escravo no Brasil? Notas a Propósito do Relatório da ONU1.
}

Marcela Soares ${ }^{2}$

De acordo com o último relatório da Organização Internacional do Trabalho de 2012, cerca de 20,9 milhões de pessoas ${ }^{3}$ estão submetidas ao trabalho escravo contemporâneo no mundo. A região da Ásia possui o maior número com 11,7 milhões ou $56 \%$ do total global, em segundo lugar está a África com 3,7 milhões (18\%), seguida pela América Latina e Caribe com 1,8 milhão de vítimas (9\%). Os países da União Europeia com 1,5 milhões (7\%), enquanto países da Europa Central, Sudeste e Leste Europeu (fora da União Europeia) e da Comunidade de Estados Independentes (CEI) têm 1,6 milhões (7\%). Há uma estimativa de 600 mil (3\%) vítimas no Oriente Médio.

Neste artigo, trabalharemos com os atuais desafios para acabarmos com o trabalho escravo contemporâneo ${ }^{4}$ no Brasil, e com elementos apontados pelo relatório da

\footnotetext{
${ }^{1}$ Sobre o específico Relatório da Relatora Especial sobre Formas Contemporâneas de Escravidão, incluindo suas causas e consequências sobre sua visita ao Brasil.(2010)

${ }^{2}$ Assistente Social, mestre e doutora em Serviço Social pela UFRJ. Professora do Departamento de Serviço Social de Niterói da UFF e pesquisadora do Grupo Pesquisa Trabalho Escravo Contemporâneo - GPTEC/UFRJ e do Núcleo de Estudos Agrários, Desenvolvimento Social e Segurança Alimentar e Nutricional- NEADS/UnB.

3 "Do total de 20,9 milhões de trabalhadores forçados, 18,7 milhões (90\%) são explorados na economia privada, por indivíduos ou empresas. Destes, 4,5 milhões (22\%) são vítimas de exploração sexual forçada e 14,2 milhões (68\%) são vítimas de trabalho forçado e exploração do trabalho em atividades econômicas, como a agricultura, a construção civil, trabalho doméstico ou trabalho em fábricas. Os restantes 2,2 milhões (10\%) estão em formas impostas pelo Estado de trabalho forçado (...)". (ILO, 2012, p. 1. tradução do autor). A OIT utiliza o termo trabalho forçado, aqui neste artigo utilizamos o termo trabalho escravo contemporâneo, verifique a nota seguinte para maiores esclarecimentos.

${ }^{4}$ Trabalho temporário sob coerção, como pretexto de dívida, existente com muita regularidade em empresas agropecuárias, principalmente desde os anos 1960. (Rezende Figueira, 2004, p. 34). Uma escravidão bem real, diariamente flagrada no Brasil nas modalidades do trabalho forçado, da servidão por dívida, da jornada exaustiva e
}

Brasiliana - Journal for Brazilian Studies. Vol. 2, n.2 (Nov 2013). ISSN 2245-4373. 
ONU, que demonstram problemáticas da situação brasileira e alguns aparentes avanços nos últimos 8 anos.

É crucial ressaltar, que vivenciamos um período de efervescência das classes trabalhadora e subalternas, a partir da chamada Jornadas de junho de 2013, quebrando um longo período de inércia ou apatia das massas, que trazem uma vasta agenda de direitos sociais que não foram cristalizados com a Constituição Federal de 1988 e de elementos que questionam as instituições burguesas, tais como as formas de organização partidária. Situação que expressa a intolerância das classes dominadas frente às precárias condições de sobrevivência e com os escândalos constantes de corrupção.

Abre-se a possibilidade de questionar e reivindicar direitos constitutivos da emancipação política, que no Brasil foram alcançados de forma incipiente e precária, arranjados com elementos arcaicos, que trazem a figura do compadrio e do favor na concretização dos direitos sociais.

Direitos fundamentais para a conquista dos direitos humanos, desconstruídos nesta longa trajetória de revitalização do capital frente a sua crise estrutural, assim imprescindíveis para o combate ao trabalho escravo contemporâneo.

\section{Trabalho Escravo Contemporâneo: Inserção periférica e dependente brasileira.}

Compreendermos o trabalho escravo contemporâneo, como uma das expressões da máxima precarização do trabalho e da violação aos direitos humanos, - reflexo da

\footnotetext{
das condições degradantes de trabalho. Para designar essa forma de relação de superexploração do trabalho têm sido utilizadas outras nomenclaturas também, como: formas de imobilização, trabalho repressivo ou coercitivo, peonagem, escravidão temporária e por dívida. Existe uma grande polêmica no âmbito acadêmico e jurídico, que gira em torno da utilização destas nomenclaturas. Após a aprovação em 2012 da PEC 438/2001 (conhecida como a PEC do confisco da terra), os interesses de ruralistas e grandes políticos da chamada Bancada ruralista, giram em torno de retroceder a conceituação dada pelo Código Penal brasileiro (no seu art. 149), revisada em 2003.
}

Brasiliana - Journal for Brazilian Studies. Vol. 2, n.2 (Nov 2013). ISSN 2245-4373. 
reinvenção de traços arcaicos que persistem na periferia do capitalismo, mas também como fruto das mudanças em curso nas relações de trabalho desde os anos 1990 no Brasil. Os traços arcaicos ou pré-capitalistas são particularidades históricas que mediatizam os nossos aspectos culturais, econômicos e políticos, que evidenciam o lugar que nosso país ocupa na divisão internacional do trabalho - enquanto um país periférico e dependente.

Pensar os desafios apontados pelo relatório da ONU em nosso país, não somente restritos ao trabalho escravo contemporâneo, mas também relativos à educação, à saúde, aos direitos sociais básicos, se faz imprescindível apontar os aspectos de construção da nossa modernidade capitalista, que fora implementada por vias não clássicas, não revolucionárias, que não se fizeram completa, mas arranjada e combinada.

Processos que não culminaram nas típicas revoluções nacionais e nas reformas democrático-burguesas (Fernandes, 2006), devido a nossa funcionalidade enquanto, inicialmente, uma formação colonial, como uma economia subsidiária da acumulação primitiva do capital no século XVI. Desenvolveu-se, por meio de "modernizações conservadoras", que desde a Independência - passando pela Proclamação da República e a chamada Revolução de 1930 -, não modificou a subalternidade de nosso país. E desencadeou a constituição de uma classe burguesa com ar autocrático, que possui cristalizado como sua segunda natureza o "mandonismo oligárquico" - ideais liberais articulados a um perfil plutocrático e patrimonialista. (Id.)

De acordo com a nossa formação periférica e dependente e com as características da nossa classe dominante, o Estado brasileiro se desenvolveu para o atendimento dos fins particulares da burguesia. Em outros termos, os interesses privados precedem e se apropriam da esfera pública estatal, por meio da anulação da fala e do dissenso - para viabilizar a sobre apropriação e a superexploração do trabalho e dos recursos naturais -, 
para assim garantir o super privilégio da classe dominante, até porque, parte do excedente econômico se destina às economias centrais (às burguesias imperialistas).

A sociedade brasileira, em seu processo de formação e desenvolvimento, é perpassada por uma trajetória de violência, de proibição da fala, da privatização do público, onde existe uma incompatibilidade profunda entre a dominação burguesa e a democracia, em outras palavras, há a constante presença da anulação da politica e do dissenso. (Oliveira, 1999)

É claro que a base estrutural do escravismo traz, ainda hoje, características marcantes, de maneira reinventada, a apropriação do corpo e a anulação do outro, a proibição da fala e o rigor da coerção estatal, como proibição da reivindicação. E todo o esforço de democratização, de construção de uma esfera pública, decorreu em boa parte da ação das classes trabalhadoras e subalternas.

A imposição do silêncio, do roubo da fala, que é apresentada pela falsa ideia de busca pela "harmonia social", expressa a anulação da política. A autocracia burguesa (iniciada por meio do golpe civil-militar de 1964), representou a busca pelo consenso imposto, a coerção para frear e derrotar a construção política que as classes trabalhadora e subalternas haviam realizado no Brasil. (Id.)

O processo de redemocratização, desencadeado pelas classes dominadas, reconstruiu a política até a Constituição Federal de 1988 e as reivindicações ganharam estatuto de direito e representaram a luta pela repartição da riqueza socialmente produzida.

Porém, a década de 1990, será marcada pela ofensiva neoliberal, que vai defender a privatização do público, objetivada pela suposta crise fiscal do Estado e pelo mecanismo da dívida pública interna, por meio da Reforma Gerencial do Estado (MARE, 1995). Uma falsa consciência de desnecessidade do público, em que a riqueza em forma de 
fundo público, sustenta a reprodução da riqueza do capital privado. (Berhing, 2003; Oliveira, 1999)

A falsa e aparente não necessidade da esfera pública desencadeia também o retrocesso de o Estado se reconstruir como espaço de interesses privados, tudo que é público é considerado como inimigo de cada indivíduo.

É por meio dessa equivocada compreensão da esfera estatal, que para superar a crise estrutural do capital ${ }^{5}$, os governantes implementam em seus Estados nacionais uma série de contrarreformas, para viabilizar a lucratividade do capital. Ou seja, há a execução de um sistema de sucção de recursos fiscais e de renda das famílias para os cofres capitalistas, assim ampliando as fontes de valor real que sustentam o empresariado por meio do capital financeiro. De acordo com Letizia (2012, p. 49-50), há um direcionamento para:

-produção centrada na exportação, para obter grandes superávits comerciais em detrimento da produção para o consumo interno (exceto nos EUA);

-gestão monetária "austera", orientada para a atração de capital externo, devendo toda republiqueta periférica "fazer a sua lição de casa", com o objetivo de obter o apreciadíssimo "grau de investimento" das agencias de avaliação do "risco-país" para o capital financeiro mundial;

\footnotetext{
${ }^{5}$ A crise estrutural do capital, que explode na década de 1970, traz a implementação de uma reestruturação por meio de uma política macroeconômica de orientação neoliberal, implementando contrarreformas privatizantes e uma reestruturação na produção. Por meio da chamada "acumulação flexível", que reduziu o trabalho assalariado, no qual se tem a garantia de direitos trabalhistas e manteve-se o trabalho precarizado, subcontratado, terceirizado, informal, com contratos temporários, o auto-emprego e até o trabalho escravo - , para diminuir os custos dos encargos sociais e fiscais da relação do assalariamento. Sobre a crise estrutural do capital, verifique em Mészáros (2009), Harvey (2011) e Letizia (2012).
}

Brasiliana - Journal for Brazilian Studies. Vol. 2, n.2 (Nov 2013). ISSN 2245-4373. 
-entrega de todos os serviços públicos possíveis a empresas privadas, nacionais e estrangeiras, indiferentemente, acompanhada de formas diversas de garantia de lucro pelo Estado;

-associação do Estado com o capital privado em todo investimento pouco lucrativo, nos quais o primeiro entra com a maior parte dos gastos e o segundo tem lucros garantidos; (...)

-titularização e expansão para o exterior das dívidas estatais, gerando um serviço eterno de pagamento de juros aos credores externos e, internamente, ampliando a transferência da riqueza dos que vivem de salário para os que vivem de rendimentos financeiros,

-liquidação gradual da seguridade social baseada no sistema de capitalização, com redução da seguridade estatal na medida ótima para abrir o maior espaço possível à seguridade privada; (...)

Uma política macroeconômica voltada para exercer direitos exorbitantes do capital sobre a receita do Estado e sobre a massa salarial - submeteram todos os países do mundo aos interesses de aparelhos de gestão estatal e instituições de finança internacional (BM e FMI), transferindo renda dos assalariados para o capital e recursos fiscais para o capital financeiro. (Id.)

Um cenário de retrocesso social, que no caso brasileiro, retroage direitos que não foram cristalizados, submetendo o nosso "Estado de mal-estar social", nos termos do Chico de Oliveira, a uma configuração de Estado penal ${ }^{6}$.

Apontadas de maneira breve a particularidade brasileira e a conjuntura atual da dinâmica do capital, podemos compreender as causas e os desafios apontados pelo relatório da ONU. Aspectos do nosso marco legal, institucional e dos programas de

${ }^{6}$ Sobre isto ver Wacquant (2007)

Brasiliana - Journal for Brazilian Studies. Vol. 2, n.2 (Nov 2013). ISSN 2245-4373. 
combate ao trabalho escravo contemporâneo devem ser analisados à luz desse solo histórico.

A história do trabalho escravo no Brasil e os marcos normativos apresentam características de que foram implementados de fora, apesar de nossa história apresentar a resistência dos escravos ${ }^{7}$ e de um pequeno setor da burguesia abolicionista. Não houve um processo revolucionário que abalasse toda a estrutura social, que transformasse todas as esferas sociais da nossa formação social: a cultura, a politica e a economia. Estas foram redesenhadas, remodeladas de acordo com os interesses externos (burguesia imperialista) e da burguesia dependente ${ }^{8}$. Assim, a modernidade fora implementada onde era inevitável e a classe dominante brasileira se aproveitou das disparidades regionais, para manter os traços arcaicos/pré-capitalistas que viabilizassem a permanência de seus privilégios.

Em relação aos nossos marcos legais, a impunidade é reflexo dessa apropriação do público e sua privatização pelas classes dominantes. Assim como, a violência contra os trabalhadores, lideranças e organizações que lutam contra o trabalho escravo contemporâneo é reflexo da apropriação do corpo, da anulação da fala e do dissenso.

Dentre as causas do trabalho escravo contemporâneo ${ }^{9}$ no meio rural, temos o não acesso a terra, um alto índice de pessoas desempregadas com baixa escolaridade,

\footnotetext{
${ }^{7}$ A exemplo do levante dos Malês em 1835. Sobre isto ver: Reis (2003)

${ }^{8}$ Obviamente que também a germinal luta de classes entre a burguesia brasileira e a classe trabalhadora irá desencadear redirecionamentos nesse processo.

${ }^{9}$ Entendemos que o trabalho escravo contemporâneo é fruto das particularidades da nossa formação social e do desenvolvimento do capitalismo periférico. E as atuais precarizações das relações de trabalho são tão significativas, que o trabalho escravo ou peonagem retoma um lugar importante na produção, a partir das terceirizações, que ocupam uma centralidade na organização produtiva. Essa perda de direitos trabalhistas e o aparecimento de formas ultrajantes de exploração do trabalho podem ser explicadas, conforme a "Lei Geral da Acumulação Capitalista", pois o sobretrabalho engrossa as fileiras de desempregados, tendo em vista que esses intensificam o sobretrabalho daqueles empregados, submetendo-os a trabalhos cada vez mais degradantes. Isso pode explicar a existência do trabalho escravo, pois os trabalhadores, sem a menor expectativa de encontrar emprego em suas cidades, aceitam qualquer proposta de trabalho.
}

Brasiliana - Journal for Brazilian Studies. Vol. 2, n.2 (Nov 2013). ISSN 2245-4373. 
direitos trabalhistas conquistados tardiamente ${ }^{10}$ e uma estrutura fundiária que permanece com a distribuição desigual da terra, com alto grau de concentração fundiária presente no território nacional, onde configura um Índice de Gini/2012 de 0,843. (Gomes \& Silva, 2013)

Como podemos atestar, entre os anos de 1975 a 2006, o grau de concentração fundiária no território brasileiro continuou quase inalterado; o índice de Gini, para a desigualdade de terra, registrado para 2006 foi de 0,856; que não difere dos índices dos anos de 1995, 1985 e 1975 que foram, respectivamente, 0,857; 0,858 e 0,855 (Hoffmann et al. apud Gomes \& Silva, 2013).

No setor têxtil, a condição do imigrante é precária e desprotegida, e o aumento acelerado do contingente de imigrantes bolivianos é consequente de uma cruel mundialização do exército industrial de reserva ${ }^{11}$ e a necessidade de superexploração do capital. Uma grande massa de trabalhadores circulando, em toda a América Latina, em busca de emprego, garantem a possibilidade de superexploração dos trabalhadores em condições de imigrantes ilegais.

\section{Conclusões e recomendações da ONU - lutas históricas da classe trabalhadora $x$ alívio da miséria}

É indispensável pensarmos as políticas sociais direcionadas a esta parcela da classe trabalhadora, que é libertada da exploração do trabalho escravo contemporâneo ou que pode vir a se tornar escrava. Tendo em vista, a inexistente ou ineficaz articulação intersetorial das políticas sociais e as causas estruturais que fazem com que os trabalhadores se submetam a este tipo de exploração.

\footnotetext{
${ }^{10}$ Sobre isto ver Ianni (2005)

${ }^{11}$ Sobre mundialização do exército industrial de reserva, ver Chesnais (2006)
}

Brasiliana - Journal for Brazilian Studies. Vol. 2, n.2 (Nov 2013). ISSN 2245-4373. 
$\mathrm{O}$ relatório da ONU analisado aborda questões centrais, que prejudicam o combate ao trabalho escravo contemporâneo, e demonstra em suas conclusões problemas como a prática política brasileira e problemáticas operacionais e organizacionais dos programas, projetos e políticas sociais, como:

o ciclo de impunidade de que gozam proprietários de terras, empresas locais e internacionais e alguns intermediadores como os "gatos" que usam trabalho escravo (...)Conflitos jurisdicionais e atrasos no sistema judiciário muitas vezes levam à prescrição e à impunidade dos perpetradores (...)A Relatora Especial também notou que existiam várias iniciativas valorosas criadas para combater a escravidão - em nível Federal e nos Estados, onde ações em nível local precisam ser melhoradas. No entanto, essas iniciativas continuam separadas e há uma necessidade geral de políticas e programas que sejam mais coordenados e complementares, de forma a aumentar sua eficácia (...)reconheceu que aqueles que defendem as vítimas têm sido constantemente ameaçados, feridos ou assassinados. Há uma necessidade geral de fortalecer a polícia (mais funcionários e treinamento) e medidas de proteção que permitam investigações efetivas, julgamentos e punições. (ONU. 2010, p.22-23)

Em relação às recomendações do relatório para a eliminação do trabalho escravo contemporâneo, apresenta elementos urgentes e imprescindíveis, tais como a PEC 438/2001 e a incorporação à lei da "lista suja", mas o relatório não defende mudanças estruturais, se limita às orientações internacionais do Banco Mundial e do FMI, 
coerentes com as perspectivas defendidas pelo economista indiano Amartya Sen ${ }^{12}$ (2008; 2011).

É notória a devastação de direitos, e essa perspectiva adotada pelo BM/FMI aparece, neste momento histórico, como uma suposta solução conciliatória entre liberdade e igualdade, uma perspectiva, que é uma variante do liberalismo ortodoxo apesar de se distinguir em aspectos não triviais. Segundo esta nova concepção, identificada como liberal revisitada, os ideais de igualdade e liberdade só podem ser compatibilizados se a igualdade for apreendida como "igualdade de oportunidades", para que todos possam ser efetivamente livres e, assim cidadãos autônomos por escolha própria. O direito a que todos têm é o direito de "aprender a pescar", ou seja, o direito a oportunidade.(Werneck Vianna, 2008)

$\mathrm{Na}$ concepção liberal revisitada, a primazia da liberdade não se associa indiscriminadamente ao primado da seletividade; ao contrário, pode conviver com sistemas universais. O outro ponto distintivo é justamente a convivência, que a segunda concorrente vê como natural, entre políticas sociais universais e políticas sociais focalizadas. Rejeita, em parte, o minimalismo de sua matriz, a concepção liberal revisitada postula a coexistência de políticas universais e políticas focalizadas, e aponta como objetivo primordial da ação pública a ampliação das oportunidades para que todos possam caminhar pelas próprias pernas. Com a prioridade de deslocar

\footnotetext{
${ }^{12} \mathrm{O}$ intelectual tentou desenvolver uma análise por meio do clássico Adam Smith, que criticasse e aperfeiçoasse as elaborações presentes na teoria utilitarista de Jeremy Bentham e na teoria da justiça de John Rawls. (Maranhão, 2010, p. 84). "Pesquisador da ONU que trabalhou ao lado do economista paquistanês Mahabub U1 Haq, na elaboração do IDH, tem sido frequentemente citado como um autor progressista, crítico do neoliberalismo, apresentador de alternativas concretas e possíveis para minimizar o atual quadro social de aumento de desemprego, da pobreza e das desigualdades. Talvez uma leitura apressada e superficial de seus textos ofereça margem para tal compreensão, já que, diferentemente de autores como Friedrich Hayek e Milton Friedman, neles comparece o reconhecimento de um certo papel do estado na resolução da dívida social atual. Porém, uma análise mais atenta de suas concepções e conceitos podem revelar o verdadeiro intento de seu esforço intelectual”. (Maranhão, 2010, p. 8384)
}

Brasiliana - Journal for Brazilian Studies. Vol. 2, n.2 (Nov 2013). ISSN 2245-4373. 
(...) a discussão da pobreza da questão social e seus elementos fundantes, para a pobreza como ausência de capacidades individuais para assegurar a vida, fundadas no pensamento de Amartya Sen (2000). Assim, a política social estaria focada nos que estão em desvantagem de capacidades - os pobres - transformando-se numa estratégia política para lidar com os que não têm condições de ingressar no mercado formal de trabalho, e moldando o comportamento político, econômico e civil do exército industrial de reserva. (Berhing, 2008, p.157)

Definida a "questão social"13 como pobreza e pobreza como carências individuais sobrepondo o papel das estruturas econômicas, sociais e políticas -, descobre-se mais um preceito essencial: políticas sociais de natureza coletiva, universais, não são as únicas nem as mais eficazes para lidar com as expressões da "questão social". Para esses autores, quando dominam o cenário da proteção social tendem a desequilibrar o orçamento fiscal, desperdiçar recursos, penalizar investimentos e a não alcançar devidamente os pobres. Devem, portanto, se restringir àquelas que propiciam igualdade de oportunidades para o exercício da liberdade, que se dirigem a indivíduos, a grupos específicos, a segmentos da população pobre, que merecem ser tratados de modo diverso em respeito às diferenças que guardam entre si.

Werneck Vianna (2008) aborda que há uma predominante concepção de política social que possui dois traços que a identificam como inovadora, e que a encaixam na categoria de legítima representante da concepção liberal revisitada. Um é o estímulo ao

\footnotetext{
${ }^{13}$ É importante destacar que o desenvolvimento capitalista produz, de forma compulsória, a chamada "questão social" e está de forma elementar determinada pela constituição própria da relação de exploração do trabalho pelo capital. A exploração apenas remete à determinação molecular da "questão social"; na sua integralidade, ela implica a intercorrência mediada de componentes históricos, políticos, culturais etc. Portanto, distintos estágios capitalistas e particularidades de formação sócio-histórica dos diversos países, assim como político-culturais determinarão a produção de diferentes expressões da "questão social"; esta não é uma consequência transitória da sociedade capitalista. A “questão social” é constitutiva do desenvolvimento do capitalismo. (Netto, 2001).
}

Brasiliana - Journal for Brazilian Studies. Vol. 2, n.2 (Nov 2013). ISSN 2245-4373. 
empreendedorismo como instrumento de "inclusão social". O outro consiste no "novo" assistencialismo, caracterizado por transferências de renda aos pobres com condicionalidades.

Amartya Sen $(2008 ; 2011)$ identifica o desenvolvimento como um processo de capacitação individual, viabilizado por uma política de desenvolvimento, que tem por base a ideia de desenvolvimento como liberdade individual, essa que não identifica a relação do ter com o fazer, ou seja, basta o ser e o fazer (capacidades individuais) dos indivíduos para se alcançar desenvolvimento. Portanto, para o autor, não é necessário um planejamento estatal keynesiano para se obter um desenvolvimento social.

Há uma alteração da análise da $\operatorname{pobreza}^{14}$, realizada por Sen, que captura as características individuais das pessoas, de forma que o indivíduo é o centro do enfoque para entender a pobreza e a desigualdade, tendo por base determinados princípios. Os argumentos de Sen (2008), viabilizam ao pensamento liberal uma nova legitimidade teórica e ideológica, pois garante com um estatuto teórico uma superficial interpretação da realidade atual.

Maranhão (2010) afirma que o foco da concepção de desenvolvimento do autor indiano não está direcionado para a desigualdade de renda, e tampouco para a questão da propriedade privada, “(já que o mercado é condição natural de liberdade), mas sim [para a] desigualdade de liberdade para acessar os benefícios de mercado." (Id, p. 90). E a solução não é a distribuição de renda, mas a oferta de "oportunidades sociais através de

\footnotetext{
${ }^{14}$ Essa alteração da análise da pobreza ocorre de acordo com as necessidades históricas do capitalismo para sair do seu processo de crise estrutural. Crise iniciada na década de 1970, que desencadeou a elaboração do receituário do Consenso de Washington de 1989, cujas "reformas" fazem parte das chamadas "condicionalidades" dos empréstimos externos do Fundo Monetário Internacional. Os pontos centrais dessa agenda eram diminuir o déficit fiscal atribuído ao gasto público (sobretudo o gasto social); promover a "reforma" do Estado, remodelando suas funções na perspectiva de aumentar a sua "eficiência" através da diminuição de custos; aumentar a "competitividade" reduzindo os custos sociais das empresas e precarizando a força de trabalho. Essas "reformas"são reformuladas e reinventadas a cada década, de acordo com o grau de enfrentamento com a classe trabalhadora.
}

Brasiliana - Journal for Brazilian Studies. Vol. 2, n.2 (Nov 2013). ISSN 2245-4373. 
políticas públicas básicas e focalizadas para que os agentes individuais possam galgar uma renda melhor na economia de mercado". (Id. Ibid., grifos do autor)

O autor indiano demonstra que cada indivíduo tem a capacidade de construir um mundo melhor individualmente, porque, para Sen, o bem-estar é uma questão de opção individual que se pode adquirir no mercado.

A teoria sobre pobreza de Sen $(2008 ; 2011)$ oferece base para acabar de vez com a ideia de revolução social, uma vez que para ele a transformação está no indivíduo, que se desenvolve e melhora, já que existem defeitos individuais ou falhas, e não um problema da estrutura social.

Como podemos identificar, a estrutura das politicas sociais brasileiras estão de acordo com o liberalismo revisitado. Frente a crise estrutural do capital, são políticas de alivio da miséria, com a precarização e assistencialização da proteção social.

O Programa Bolsa Família apenas ameniza a extrema pobreza, porque se considerarmos o valor dos benefícios, que variam entre $R \$ 32$ e $R \$ 306^{15}$, são bem inferiores do que um salário-mínimo ( $\mathrm{R}$ \$ 678). E, se analisarmos o valor do nosso salário minimo, este já não garante as condições básicas de sobrevivência, pois de acordo com o Dieese, o salário-mínimo para suprir as necessidades do trabalhador e de sua família deveria ser 4,05 vezes maior do que o vigente ${ }^{16}$.

Devemos nos atentar à desigualdade social, inerente a sociedade capitalista, mas que é alavancada pelo nosso sistema tributário regressivo. Os ricos no Brasil continuam participando desigualmente da estrutura tributária, uma vez que sua participação não ocorre proporcionalmente a sua capacidade contributiva e porque grande parte de suas rendas estão isentas de tributação. Ressalta-se também, que a participação dos lucros

\footnotetext{
${ }^{15}$ Hoje com o Brasil Carinhoso, esses valores são maiores, mas estão restritos a uma determinada parcela dos beneficiários. Sobre isto verifique em http://www.mds.gov.br/brasilsemmiseria/brasil-carinhoso

${ }^{16}$ De acordo com os dados do Dieese referentes ao mês de julho de 2013.
}

Brasiliana - Journal for Brazilian Studies. Vol. 2, n.2 (Nov 2013). ISSN 2245-4373. 
consistentemente aumentou sua proporção na renda nacional dos primeiros oitos anos deste século.

O financiamento do Estado brasileiro é feito por meio de recolhimento de tributos que incidem sobre a renda dos assalariados e dos servidores públicos, além da elevada carga tributária regressiva que atinge a população mais pobre. Ao mesmo tempo em que a maior parcela do orçamento é destinada ao capital financeiro ${ }^{17}$, por meio do pagamento de juros e amortização da dívida pública ${ }^{18}$. Na verdade, o Estado brasileiro retira dos pobres, por meio de tributos regressivos, para redistribuir aos ricos, por meio de pagamentos de juros. (Salvador; Amorim, 2010)

É primordial também a avaliação dos meios para reinserir os trabalhadores libertados do trabalho escravo. E o que se identifica é que os programas de geração de emprego e renda são precários e que o nosso sistema público de emprego além de ser desintegrado, possui um baixíssimo investimento e traz alternativas precárias aos trabalhadores. ${ }^{19}$

\footnotetext{
17 "no Governo Lula verifica-se a dominação financeira. Esta pode ser entendida como a ascendência do setor financeiro, inclusive sobre os outros setores dominantes. A dominação financeira tem expressão concreta na apropriação do excedente econômico. Para ilustrar, a taxa média de rentabilidade (lucro/patrimônio líquido) dos 50 maiores bancos é sempre superior à das 500 maiores empresas em todos os anos do período 2003-10 [...]. Neste período a taxa média de rentabilidade das maiores empresas é $11,0 \%$ enquanto a taxa dos bancos é $17,5 \%$. O diferencial de rentabilidade entre o setor real e o setor financeiro está associado ao diferencial de acumulação de capital entre estes setores. A dominação financeira é evidenciada pela crescente relação entre os ativos totais dos 50 maiores bancos e das 500 maiores empresas do país no período 2003-10 [...]. Esta relação aumenta de 0,99 em 2002 para 1,74 em 2010. Os bancos se beneficiam do abuso do poder econômico, leniência do Banco Central, certeza da impunidade e da política monetária restritiva caracterizada por elevadas taxas de juro. Para ilustrar, levantamento recente mostra que Turquia e Brasil são os dois países que têm os mais elevados custos da dívida pública em amostra de 24 países. O custo médio da dívida pública para a amostra é de 4,\% enquanto que no Brasil é de 8,6\%. Isto faz com que a relação entre pagamento de juros da dívida pública e o PIB no Brasil seja o segundo maior da amostra (superado pela Grécia, que no momento do levantamento encontrava-se em plena crise financeira). A média desta relação para a amostra é $2,0 \%$ e no Brasil é 5,1\%”. (Gonçalves, 2011, p. 18)

${ }^{18}$ Verifique o Gráfico 2 nos anexos. Dados do site auditoriacidada.org.br. Acesso em 13 de junho de 2013.

${ }^{19}$ É crucial destacar que o problema do desemprego não é apenas um problema de falta de qualificação, em que é entendido pelo pensamento hegemônico conservador como um problema moral, individual, de falta de empregabilidade, por exemplo.
}

Brasiliana - Journal for Brazilian Studies. Vol. 2, n.2 (Nov 2013). ISSN 2245-4373. 
Existe um conjunto de problemas operacionais do Sistema Nacional de Emprego (Sine), tais como: a falta de integração entre os programas sociais ${ }^{20}$; pífio financiamento; ineficaz intervenção em setores do mercado de trabalho que demandam qualificação ${ }^{21}$, entre outros problemas

O que é oferecido à classe trabalhadora por meio da política de geração de emprego e renda?

a) Empregos com salários baixos, quando se tem a garantia dos direitos trabalhistas;

b) o autoemprego em cooperativas, sem direitos garantidos e com salários mensais, que podem ser equivalentes a $\mathrm{R} \$ 75,00^{22}$;

c) o autoemprego como empreendedor individual, em que o empreendedor tem que arcar com os ônus dos custos sociais dos seus direitos trabalhistas; e

d) o acesso ao seguro-desemprego e indenizações aos trabalhadores libertados de condições análogas a da escravidão e para aqueles que foram demitidos sem justa-causa.

No caso do combate ao trabalho escravo ainda prevalecem iniciativas ${ }^{23}$, por meio da parceria público-privada, que apesar de serem ações fundamentais e atenderem às demandas imediatas de um contingente dos trabalhadores libertados, não possuem uma regularidade e legalidade de uma política pública que garanta a efetividade de seus objetivos e uma maior abrangência.

\footnotetext{
${ }^{20} \mathrm{O}$ conjunto dos programas de geração de emprego e renda não são integrados, não há relação direta do Proger com o PNQ, e muito menos com o Sistema Nacional de Emprego (Sine). E que estão longe de cumprir sua tarefa de promoção do desenvolvimento justo e solidário do Brasil. Verifique em (Marinho et al [orgs.], 2010) e Soares (2012)

${ }^{21}$ O Sistema público de emprego brasileiro não implementa programas de qualificação adequados às necessidades do mercado de trabalho, e esses são direcionados à iniciativa privada.

${ }^{22}$ Ver tabela 2 nos anexos.

23 Aqui podemos mencionar o Instituto Carvão Cidadão e o Ação Integrada para Qualificação e Reinserção Profissional dos Resgatados do Trabalho Escravo elou em Situação de Vulnerabilidade em Mato Grosso.
}

Brasiliana - Journal for Brazilian Studies. Vol. 2, n.2 (Nov 2013). ISSN 2245-4373. 
Afirmamos que apesar do aumento da maior formalização das relações de trabalho na absorção do aumento da população ativa, não ocorreram mudanças estruturais no mercado de trabalho brasileiro nos governos Lula, porque a evolução do saldo de empregos não foi suficiente para reverter as características de destruição dos direitos trabalhistas iniciada na década de 1990. Do mesmo modo, como existiu um aumento do número de trabalhadores com carteira assinada, houve também o crescimento do número de trabalhadores sem carteira assinada e os por conta própria

Nota-se que, diferentemente dos países centrais ${ }^{24}$, o Brasil não terminou constituindo um sistema público nacional de emprego, com medidas articuladas e integradas entre si e universalizadas para o conjunto do mercado de trabalho (formal e informal). Na verdade o que se constituiu foi uma mera agregação de iniciativas, que opera muitas vezes em regime de sobreposição no atendimento de certas "clientelas", com efetividade e eficácia discutidas.

Outro ponto fundamental é a reforma agrária ${ }^{25}$ que podemos considerá-la pífia, tendo em vista que a política pública de fomento está voltada preferencialmente ao agronegócio e tem destinado a parte mais substantiva do crédito e financiamento, além dos melhores esforços da pesquisa e desenvolvimento, ao segmento que, voltado à exportação, contribui com os resultados do PIB brasileiro

Portanto, o governo ao investir e manter uma política de estímulo e apoio à expansão das "commodities" com o patrocínio do capital financeiro, promove o deslocamento da acumulação de capital para setores com o controle da terra e

\footnotetext{
${ }^{24}$ Verifique em Dedecca et al. (2007)

25 "no Brasil existem 180 mil famílias acampadas, à espera de desapropriação de áreas para criação de assentamentos; $80 \%$ das famílias hoje assentadas estão endividadas por conta da política de crédito existente no campo, o Pronaf".(Artigo: Em anúncio do Plano Safra, governo reafirma seu descaso com a Reforma Agrária Disponível em:http://www.correiocidadania.com.br./index.php?option=com_content\&view=article\&id=8471:emanuncio-do-plano-safra-governo-reafirma-seu-descaso-com-a-reforma-agraria\&catid=33:noticias-em-destaque Acesso em 14 de junho de 2013)
}

Brasiliana - Journal for Brazilian Studies. Vol. 2, n.2 (Nov 2013). ISSN 2245-4373. 
portadores da renda fundiária. Assim, sob essas diretrizes que reforçam a reprimarização da nossa economia como estratégia de desenvolvimento, o governo brasileiro não só mantém inalteradas as contradições que conformam a nossa questão agrária ${ }^{26}$ como, também, garante o retrocesso social.

\section{Considerações Finais}

Com tudo isso posto, para solucionarmos o trabalho escravo ${ }^{27}$ se faz necessária a defesa da esfera pública e de direitos ${ }^{28}$, que são culturalmente entendidos como favor e exercidos pela prática do compadrio. Devemos romper com as amarras arcaicas e exigir a permissão do dissenso e da fala, que sempre foi roubada e cerceada pelas classes dominantes. Não podemos permitir essa apropriação da esfera pública pelas classes dominantes, que permitem a naturalização da impunidade.

Temos que combater as causas estruturais, dessa forma, deve-se apontar que as metas do governo, de acordo com a orientação macroeconômica do BM/FMI aos países

\footnotetext{
${ }^{26}$ O censo agropecuário de 2006 apontou que dos 5,17 milhões de estabelecimentos existentes, 84,4 \% (4,36 milhões) eram da agricultura familiar. Este contingente de produtores ocupava uma área de 80,25 milhões de hectares, que representava $24,3 \%$ da área ocupada pelos empreendimentos agropecuários. Por conseguinte, os estabelecimentos não familiares apesar de representarem somente 15,6\% dos estabelecimentos ocupavam 75,7\% da área .A agricultura familiar ocupava somente um quarto, enquanto, a patronal três quartos da área total dos estabelecimentos, confirmando que o predomínio fundiário da economia patronal contrasta com predomínio demográfico da economia familiar. Apesar da defasagem temporal dos dados do Censo Agropecuário de 2006, esse quadro fundiário rural permanece atual. (Gomes; Silva, 2013, p.10)

${ }^{27}$ O mês de junho de 2013 no cenário brasileiro, foi um período histórico, poderíamos caracterizá-lo por uma conjuntura de efervescência política, de ascenso do dissenso e busca por fala na esfera pública. Vivenciamos um momento propício para a aprovação em todas as esferas da PEC do trabalho escravo (438/2001), mas devemos nos engajar na disputa da definição do trabalho escravo, que obviamente a bancada ruralista fará jus nesta disputa de colocá-lo definido com as configurações existentes da escravidão colonial.

28 “Os indivíduos não nascem com direitos (uma noção, aliás, reafirmada em 1948 na Declaração dos Direitos da ONU). Os direitos são fenômenos sociais, são resultado da história. Hegel tem plena razão quando diz que só há direitos efetivos, ou liberdades concretas, no quadro da vida social, do Estado. As demandas sociais, que prefiguram os direitos só são satisfeitas quando assumidas nas e pleas instituições que asseguram uma legalidade positiva." (Coutinho, 1997)
}

Brasiliana - Journal for Brazilian Studies. Vol. 2, n.2 (Nov 2013). ISSN 2245-4373. 
periférico-dependentes, são priorizar políticas focalizadas de alívio da fome e da miséria em detrimento de um sistema de proteção social universal.

O processo atual de efervescência política que vivenciamos, permite-nos resgatarmos a defesa de direitos, presente na histórica agenda da classe trabalhadora, tais como:

- educação pública, gratuita e de qualidade;

- qualificação dos trabalhadores em setores que demandem força de trabalho;

- aumentar o corpo de funcionários públicos na fiscalização das condições de trabalho,

- resgatar o controle social, enquanto direito constitucional;

- pressionar o governo para redirecionar suas prioridades, uma vez que o mesmo destina metade do orçamento publico para pagar juros da dívida pública.

Reafirma-se a imprescindível luta por direitos civis, políticos e sociais ${ }^{29}$ (pela emancipação política - reformas democrático-burguesas), esses últimos são cruciais para o fim do trabalho escravo. Porém, é importante reconhecermos os limites postos pela sociedade capitalista à concretização desse conjunto de direitos. Por isso, se faz necessária a não conformação com a realidade que se apresenta. "É necessário criar homens sóbrios, pacientes, que não se desesperem diante dos piores horrores e não se exaltem em face de qualquer tolice. Pessimismo da inteligência, otimismo da vontade" (Gramsci, 2006, p.267).

Somos muitos milhões de homens e mulheres comuns e podemos formar uma muralha com nossos corpos de sonho e margaridas (Gullar, 1963) na luta pela verdadeira emancipação humana.

\footnotetext{
${ }^{29}$ Políticas públicas, que garantam o acesso à educação, saúde, habitação com saneamento básico, ou seja, a concretização das ações e direitos previstos no Título VIII Da ordem social, da nossa Constituinte.
}

Brasiliana - Journal for Brazilian Studies. Vol. 2, n.2 (Nov 2013). ISSN 2245-4373. 


\section{Referências bibliográficas}

Berhing, E. R. 'Trabalho e Seguridade Social: o neoconservadorismo nas políticas sociais.' In: Behring, E. R. \& Tenório de Almeida, M.H. Trabalho e seguridade social, São Paulo, Cortez, 2008.

.'Crise do capital, fundo público e valor'. In: Boschetti et al (orgs.) Capitalismo em crise, política social e direitos. São Paulo, Cortez, 2010.

. 'Trabalho e Seguridade Social: o neoconservadorismo nas políticas sociais'. In: Behring, E. R. \& Tenório de Almeida, M.H. Trabalho e seguridade social, São Paulo, Cortez, 2008.

Paulo: Cortez, 2003.

Chesnais, F. Les dettes illégitimes - quand les banques font main basse sur les politiques publiques. Paris, Raisons D’Agir, 2011.

. A mundialização do capital. São Paulo: Xamã, 1996

- 'A mundialização do Exército Industrial de Reserva'. In: Revista $O$ Comuneiro, no. 3, Setembro de 2006.

Coutinho, C.N.' Notas sobre cidadania e modernidade'. Revista Praia Vermelha. Rio de Janeiro: Pós-Graduação da Escola de Serviço Social da UFRJ, Vol.1 n.1. 1997.

Dedecca, C.; Barbosa, A.; Moretto, 'A. Transformações recentes do sistema público de emprego nos países desenvolvidos tendências e particularidades'. In: Oliveira, R. (Org.). Novo momento para as comissões de emprego no Brasil? Sobre as condições da participação e controle sociais no Sistema Público de Emprego em construção. Volume 1. São Paulo: A+ Comunicação, 2007.

Fernandes, Florestan. A revolução Burguesa no Brasil - Ensaio de interpretação sociológica. 2o Ed. Rio de Janeiro: Editora Guanabara, 1976.

. O que é Revolução? São Paulo: Brasiliense, 1981.

Brasiliana - Journal for Brazilian Studies. Vol. 2, n.2 (Nov 2013). ISSN 2245-4373. 
. Capitalismo Dependente e Classes sociais na América Latina. 4º Ed. São Paulo: Global Editora, 2009.

Gomes, N.N.J.; Silva, R.P. Balança comercial do agronegócio e a questão fundiária. In: Anais do XVIII Encontro Nacional de Economia Política. 2013.

Gonçalvez, R. Governo Lula e o Nacional-desenvolvimentismo às Avessas. IE/UFRJ. Rio de Janeiro. 2011.

Gramsci, A. Cadernos do cárcere. 4.ed. Rio de Janeiro: Civilização Brasileira, 2006. v.2.

Gullar, F. Dentro da noite veloz - Poema sujo. São Paulo, Círculo do Livro, s/d.

Harvey, D. O enigma do capital. São Paulo, Boitempo, 2011.

Hay, E. J. Just-in-time: um exame dos novos conceitos de produção. Maltese editorial, São Paulo, 1992.

Ianni, O. 'A formação do proletariado rural no Brasil - 1971'. In: Stédile J. P. (org.) A questão agrária no Brasil: o debate na esquerda - 1960-1980, São Paulo: Expressão popular, 2005.

IPEA. Nota técnica: Uma análise das diferenças entre as estatísticas do mercado de trabalho sobre a variação da ocupação formal metropolitana - pme e caGed. mercado de trabalho, $\mathrm{n}^{\circ} 43, \mathrm{I}$ mai. 2010

ILO (International Labour Organization) Global estimate of forced labour Executive summary. Geneva, 2012

Letizia, V. A grande crise rastejante.Sao Paulo: Caros Amigos editora, 2012.

Maranhão, C. 'Desenvolvimento social como liberdade de mercado: Amartya Sen e Renovação das promessas liberais'. In: Mota, A.E. (orgs.) As ideologias da contrarreforma e o serviço social. Recife, Ed, UFPE, 2010.

MARE - Ministério da Administração Federal e Reforma do Estado. Plano Diretor da Reforma do Aparelho do Estado. Brasília: Imprensa Nacional, novembro 1995. Plano aprovado pela Câmara da Reforma do Estado da Presidência da República em setembro de 1995.

Brasiliana - Journal for Brazilian Studies. Vol. 2, n.2 (Nov 2013). ISSN 2245-4373. 
Marinho, D.N.C. et al. (orgs.) Políticas públicas de emprego no Brasil: avaliação externa do Programa Seguro-Desemprego. Brasília, Verbis- MTE/UnB, 2010

Marx. K. O capital, V. I, t. 2, São Paulo, Abril Cultural, 1984.

Mészáros, I. A crise estrutural do capital. São Paulo, Boitempo, 2009.

Netto, J. P. ‘Desigualdade, pobreza e Serviço Social'. In: Revista Em Pauta, FSS/UERJ, №19, 2007.

.'Cinco notas a propósito da "questão social"'. In: Temporalis, Brasília, ABEPSS, ano 2 , n. 4 , p. 41-49, 2001

Netto, J. P. \& Braz, M. Economia política: uma introdução crítica. Rio de Janeiro, Cortez, $2^{a}$ ed. 2007.

Oliveira, F. 'Privatização do Público, destituição da fala e anulação da política: o totalitarismo neoliberal'. In: Oliveira, Francisco e Paoli, Maria Célia. Os sentidos da democracia. Políticas do dissenso e hegemonia global. São Paulo, Editora Vozes/FAPESP, 1999.

ONU (United Nations).Relatório da Relatora Especial sobre Formas Contemporâneas de Escravidão, incluindo suas causas e conseqüências sobre sua visita ao Brasil.Geneva, 2010

Prado Júnior, C. Formação do Brasil Contemporâneo. São Paulo: Editora Brasiliense, 2004. . A Revolução Brasileira. São Paulo: Expressão Popular, 2009.

Reis, J, J. Rebelião Escrava no Brasil. A história do levante dos Males em 1835. são Paulo: Companhia das Letras, 2003.

Rezende Figueira, R. Pisando fora da própria sombra - A escravidão por dívida no Brasil contemporâneo, Civilização Brasileira, Rio de Janeiro, 2004.

Salvador, E.; Amorim, A. 'Abordagens das desigualdades socioeconômicas no Brasil do século XXI’. In: Revista em pauta, Rio de Janeiro, vol. 8, nº 26, p.31-48, 2010.

Sen, A. A ideia de justiça. São Paulo, Companhia das Letras, 2011.

Brasiliana - Journal for Brazilian Studies. Vol. 2, n.2 (Nov 2013). ISSN 2245-4373. 
- Desenvolvimento como Liberdade. São Paulo, Companhia das Letras, $7^{\mathbf{a}}$ reimpressão, 2008.

Silva, M. S. 'Trabalho escravo - uma realidade na cadeia produtiva de corporações com a chamada "responsabilidade social"'. In: Olhares sobre a escravidão contemporânea - novas contribuições críticas. Cuiabá, EdUFMT, 2011

Soares, M. A Política de Geração de Emprego e Renda no Octênio 2003 - 2010: Degradação sob o véu da liberdade. Programa de Pós-graduação em Serviço Social. RJ, ESS/UFRJ. 2012

. As políticas de geração de emprego e renda no Brasil: o arcaico reatualizado. In: Boschetti et al (orgs.) Capitalismo em crise, política social e direitos. São Paulo, Cortez, 2010.

Wacquant, Loic. Punir os pobres: a nova gestão da miséria nos Estados Unidos. Rio de Janeiro, Revan, 2007.

Werneck Vianna, M. L. T. 'A nova política social no Brasil: uma prática acima de qualquer suspeita teórica?'. In: Praia Vermelha, Rio de Janeiro: UFRJ, n. 18, p.120-144, jan./jun. 2008. 


\section{ANEXOS}

\section{Gráfico 1}

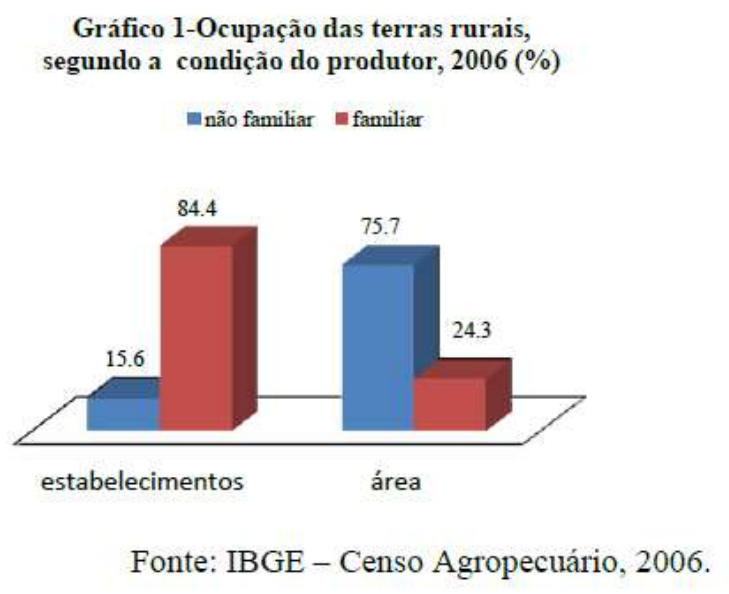

Tabela 1

Tabela 1. Estrutura Fundiária Brasil 2012

\begin{tabular}{c|c|c|c|c|c}
\hline $\begin{array}{c}\text { Estrato } \\
\text { de Área (ha) }\end{array}$ & \multicolumn{2}{|c|}{ Imóveis } & \multicolumn{2}{|c|}{ Área } & $\begin{array}{c}\text { Área } \\
\text { Média } \\
\text { (ha) }\end{array}$ \\
\hline Menos de 10 & 1.874 .969 & 34,10 & $8.834 .571,15$ & 1,46 & 4,7 \\
10 a 100 & 2.863 .773 & 52,08 & $95.186 .129,26$ & 15,72 & 33,2 \\
100 a 1000 & 678.462 & 12,34 & $181.757 .801,33$ & 30,02 & 267,9 \\
1000 a 10000 & 79.228 & 1,44 & $194.821 .102,90$ & 32,18 & $2.459,0$ \\
10000 a 100000 & 1.878 & 0,03 & $43.467 .154,54$ & 7,18 & $23.145,4$ \\
Mais de 100000 & 225 & 0,004 & $81.320 .986,88$ & 13,43 & $361.426,6$ \\
TOTAL & 5.498 .535 & & $605.387 .746,06$ & & 110,1 \\
\hline
\end{tabular}

Fonte: INCRA. Sistema Nacional de Cadastro Rural 


\section{Gráfico 2}

Orçamento Geral da União - Executado em 2012 - Total = R \$ 1,712 trilhão

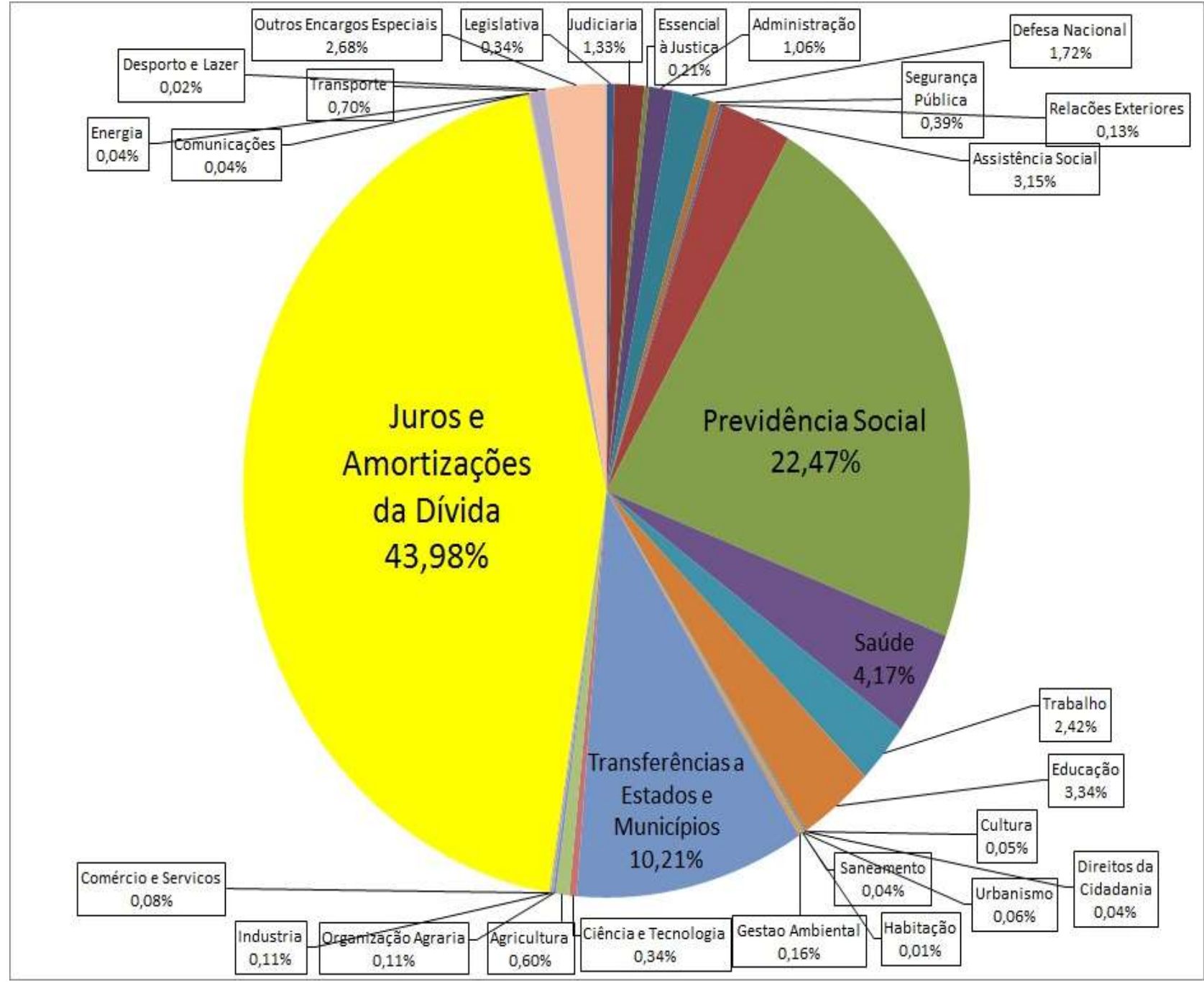

Fonte: Senado Federal - Sistema SIGA BRASIL - Elaboração: Auditoria Cidadã da Dívida, Site: http://www.auditoriacidada.org.br/e-por-direitos-auditoria-da-divida-jaconfira-o-grafico-do-orcamento-de-2012/ - Acesso em março de 2013 


\section{Tabela 2}

\begin{tabular}{|c|c|c|}
\hline \multicolumn{3}{|c|}{$\begin{array}{c}\text { REMUNERAC ÃO MÉDIA MENSAL DE SÓCIOS(AS) } \\
\text { QUE TRABALHAM NO EES }\end{array}$} \\
\hline FAIXA DE REMUNERACÃO & EES \% & MÉDIA (R\$) \\
\hline Até 1/2 SM (Salário Mínimo) & 38 & 75.00 \\
\hline$+d e 1 / 2$ a 1 sM & 24 & 217,00 \\
\hline+ de 1 a $25 \mathrm{sm}$ & 26 & 389,00 \\
\hline$+d e 2$ a $5 \mathrm{sm}$ & 10 & 896,00 \\
\hline+ de 5 SM & 2 & 2.837.00 \\
\hline TOTAL & $100 \%$ & 166,00 \\
\hline \multicolumn{3}{|c|}{$\begin{array}{l}\text { ORs, } 1 \text { i: } 59 \% \text { dos EES indicaram que remuneram os sócios(as) que trabalham ou atuam } \\
\text { no empreendimento. No entanto, } 50 \% \text { do total de EES indicou o valor medio da } \\
\text { remuneracáo mensal. } \\
\text { Obs, 2: Foi considerado o valor do Salário Minimo (SM) de } 2007 \text { (RS } 380,00 \text { ) }\end{array}$} \\
\hline
\end{tabular}

Fonte: Dados do Sistema Nacional de Informações de Economia Solidária - SIES 2008

\section{Tabela 3}

\begin{tabular}{|c|c|c|}
\hline \multicolumn{2}{|c|}{ 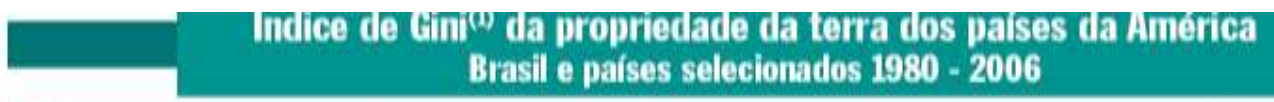 } & TABELA 4 \\
\hline Pais & Gini & \\
\hline Argentina & 0,850 & \\
\hline Bahamas & 0,872 & \\
\hline Barbados & 0,928 & \\
\hline Bolivia & 0,768 & \\
\hline Brasil & 0,854 & \\
\hline Canadá & 0,640 & \\
\hline Colômbia & 0,774 & \\
\hline EUA & 0,780 & \\
\hline Jamaica & 0,790 & \\
\hline Panamá & 0,750 & \\
\hline Paraguai & 0,930 & \\
\hline Porto Rico & 0,776 & \\
\hline Uruguai & 0,790 & \\
\hline
\end{tabular}

Brasiliana - Journal for Brazilian Studies. Vol. 2, n.2 (Nov 2013). ISSN 2245-4373. 